\title{
The cyclops and the mermaid: an epidemiological study of two types of rare malformation*
}

\author{
Bengt Källén, Eduardo E Castilla, Paul A L Lancaster, Osvaldo Mutchinick, \\ Lisbeth B Knudsen, María Luisa Martínez-Frías, Pierpaolo Mastroiacovo, \\ Elisabeth Robert
}

\begin{abstract}
Department of Embryology, University of Lund, Biskopsgatan 7, S-223 62 Lund, Sweden. B Källén

ECLAMC/Genetica/ Fiocruz, Rio de Janeiro, Brazil, and IMBICE, Casilla 403, 1900 La Plata,

Argentina.

E E Castilla

AIH National

Perinatal Statistics

Unit, Building A27,

University of Sydney,

Sydney, NSW 2006,

Australia.

P A L Lancaster

RYVEMCE

Abstract

Infants with cyclopia or sirenomelia are born at an approximate rate of 1 in 100000 births. Eight malformation monitoring systems around the world jointly studied the epidemiology of these rare malformations: 102 infants with cyclopia, 96 with sirenomelia, and one with both conditions were identified among nearly 10.1 million births. Maternal age is somewhat increased for cyclopia, indicating the likely inclusion of some chromosomally abnormal infants which were not identified. About half of the infants are stillborn. There is a female excess among infants with cyclopia. Excess twinning occurred for cyclopia and possibly also for sirenomelia. An analysis of associated malformations indicates the similarity between the two conditions, which is in agreement with recent embryological analysis.
\end{abstract}

Departamento de

Genética, Instituto

Nacional de Nutrición

Salvador Zubíran,

Vasco de Quiroga 15,

Tlalpan, 14000 Mexico

DF, Mexico.

O Mutchinick

National Board of

Health, Amaliegade

13, PO Box 2020,

DK-1012 Copenhagen,

Denmark.

L B Knudsen

Hospital Universitario

San Carlos,

INSALUD, ECEMC

Facultad de Medicina,

Universidad

Complutense, 28040

Madrid, Spain

M L Martínez-Frias

IPIMC, Servizio

Epidemiologia e

Clinica Difetti

Congeniti, Policlinico

Universitario A

Gemelli, Largo

Gemelli 8, 00168

Rome, Italy.

P Mastroiacovo

Institut Européen des Génomutations, 86

Rue Edmond Locard,

F-69005 Lyon, France.

E Robert

Correspondence to

Dr Källén.

Received 18 February 1991 Revised version accepted 15 April 1991.
A recent paper ${ }^{1}$ reported an interpretation of cyclopia and symmelia, based on a detailed embryological study of human embryos and published reports. The authors pointed out a number of similarities in the development of these two lethal conditions. They both arise by a failure of lateralisation of rudiments, the early brain rudiment, which gets its laterality from the influence of the prechordal mesoderm, ${ }^{2}$ and the 'caudal eminence', the caudal continuation of the primitive node and therefore also a basic structure in the development of axial mesoderm. ${ }^{3}$

Cyclopia is an extreme form of holoprosencephaly, which covers a broad spectrum of conditions from cyclopia to infants who are externally normal but have more or less pronounced disturbance of the pairing of the brain hemispheres. ${ }^{4}$ Similarly, symmelia or sirenomelia is an extreme form of a spectrum of malformations which have been summarised as the caudal regression malformation complex that spans sirenomelia to kidney agenesis or even anal atresia. ${ }^{56}$ The delimitation of holoprosencephaly is difficult ${ }^{4}$ which is reflected in the fact that data on its prevalence at birth vary considerably. Similarly, the actual prevalence at birth of the caudal regression malformation

*The malformation monitoring programmes that participated in this study are all members of the International Clearinghouse for Birth Defects Monitoring Systems. complex depends on which forms are included, and also on the frequency with which necropsy is performed on infants dying in the neonatal period. However, the two extreme forms, cyclopia and sirenomelia, are easily recognised and usually clearly defined, but both forms are very rare and it is therefore difficult to collect material large enough to permit detailed epidemiological studies.

We have collected such material by using data from eight malformation monitoring systems around the world, all members of the International Clearinghouse for Birth Defects Monitoring Systems, ${ }^{7}$ and we report some findings on the prevalence at birth, other epidemiological features, and associated malformations.

\section{Material and methods}

Data were collected from the following eight malformation monitoring systems which will be described very briefly. Australia: a national, population based monitoring system covering some 240000 annual births. ${ }^{8}$ Denmark: a national, population based registry of congenital malformations covering approximately 55000 annual births. ${ }^{9}$ France, Rhone-AlpsAuvergne (RAA): a regional, population based monitoring system based on nearly 90000 annual births. ${ }^{10}$ Italy, IPIMC: a hospital based monitoring system including reports from 147 hospitals and covering approximately 130000 annual births (about $25 \%$ of all Italian births). ${ }^{11}$ Mexico: a hospital based monitoring system including 21 hospitals in 11 cities with an annual birth rate of approximately $50000 .{ }^{12}$ South America, ECLAMC: a hospital based monitoring system including approximately 70 hospitals in all South American countries and covering a total number of annual births of about $215000 .^{13}$ Spain, ECEMC: a hospital based monitoring system including reports from 45 hospitals, covering nearly 60000 annual births (about $15 \%$ of all Spanish births). ${ }^{14}$ Sweden: a national, population based registry of congenital malformations covering approximately 100000 annual births. ${ }^{15}$

From each registry, data were extracted for the two conditions according to the following definitions. Cyclopia: infants born with one orbit in the middle of the face and with one or two eyes. Known chromosome anomalies are not included (because in some programmes they are often registered only as such), but a 
Table 1 Number of cases and number of births recorded in each programme (rates per 100000 births).

\begin{tabular}{|c|c|c|c|c|c|c|}
\hline \multirow[b]{2}{*}{ Programme } & \multirow[b]{2}{*}{ Years } & \multirow{2}{*}{$\begin{array}{l}\text { No of } \\
\text { births }\end{array}$} & \multicolumn{2}{|c|}{ Cyclopia } & \multicolumn{2}{|c|}{ Sirenomelia } \\
\hline & & & No & Rate & No & Rate \\
\hline $\begin{array}{l}\text { Australia } \\
\text { Denmark } \\
\text { France, RAA } \\
\text { Italy, IPIMC } \\
\text { Mexico } \\
\text { South America } \\
\text { Spain } \\
\text { Sweden } \\
\text { Total }\end{array}$ & $\begin{array}{l}1982-1989 \\
1983-1988 \\
1976-1987 \\
1983-1988 \\
1978-1988 \\
1967-1989 \\
1976-1989 \\
1965-1988\end{array}$ & $\begin{array}{r}1945888 \\
328254 \\
943579 \\
824478 \\
358590 \\
2278771 \\
728368 \\
2258613 \\
10097383\end{array}$ & $\begin{array}{c}23 \\
0 \\
5 \\
11 \\
8 \\
30 \\
6^{*} \\
20 \\
103\end{array}$ & $\begin{array}{l}1 \cdot 2 \\
0.5 \\
1 \cdot 3 \\
2 \cdot 2 \\
1 \cdot 3 \\
0 \cdot 8 \\
0.9 \\
1.03\end{array}$ & $\begin{array}{r}22 \\
2 \\
7 \\
5 \\
3 \\
32 \\
7^{*} \\
19 \\
97\end{array}$ & $\begin{array}{l}1 \cdot 1 \\
0 \cdot 6 \\
0 \cdot 7 \\
0 \cdot 6 \\
0 \cdot 8 \\
1 \cdot 4 \\
1 \cdot 0 \\
0 \cdot 8 \\
0 \cdot 96\end{array}$ \\
\hline
\end{tabular}

*One infant had both cyclopia and sirenomelia.

special study was made of trisomy 13 . Sirenomelia: complete or partial fusion of the lower limbs.

In general the conditions under study are easily defined and clear cut. Two infants with a proboscis and without eyes were reported but not included because they did not fulfil the working definition, even though they actually may represent the most severe forms. Similarly, an infant with rotated lower limbs, and therefore with feet facing backwards, was not included. These few borderline cases do not affect the registered rates much. Fewer than $10 \%$ of the cases of each type of malformation were karyotyped (nine with cyclopia, six with sirenomelia).

For each infant information was given (when available) on date of birth, maternal and paternal age at birth, parity, sex, birth weight, survival (stillborn, liveborn dying in the perinatal period, liveborn surviving the perinatal period), necropsy, whether cytogenetic investigation was performed, and multiple birth, in which case sex and status of co-twin or cotriplets. Population data (when available) were also given for these variables.

Stillbirths were not included in the Spanish material until 1980 and in the South American material until 1978. Stillbirth definition varied: in Australia, all stillbirths are registered after the 20th completed week, in Denmark, France, and Sweden after the 28th week, in Italy after 180 days, while in Mexico, Spain, and South America the definition is a birth weight of $500 \mathrm{~g}$ or more.

\section{Results}

\section{PREVALENCE AT BIRTH}

The total number of births which represents the denominator is given in table 1 for each programme. A total of 103 infants with cyclopia was identified. This gives a crude rate of 1.03 per 100000 births, but as roughly onethird of the identified cases were stillbirths and these were not included in part of the South American and Spanish programmes (a total of 873897 births before inclusion of stillbirths), the rate will be somewhat underestimated. By adding $1 / 3$ of cases for those programmes for that period, the true rate can be estimated to be 1.05 per 100000 .

Similarly, there were 97 infants reported with sirenomelia, which gives a crude rate of 0.96 per 100000 births, but because about one-third of the cases were stillbirths, the true rate is probably higher (estimated to be 0.99 per 100000 births).

Fig 1 compares the recorded numbers of cyclopia and sirenomelia in the different programmes. It can be seen that the recorded differences in rate (table 1 ) may well be explained by random fluctuations.

Table 2 shows the recorded number of infants with trisomy 13 , how many of them were described with respect to the malformations present, and how many of these had cyclopia. It can be seen that cyclopia occurred in $2.7 \%$ of all trisomy 13 infants where malformations were described. As the rate of recorded trisomy 13 is about 1 in 17200 , it can be estimated that to the rate of cyclopia described above can be added $0 \cdot 15$ per 100000 of cyclopia recorded as trisomy 13, giving a total of 1.20 per 100000 .

Fig 2 shows the time trend: for both malformations the rates up to 1974 were higher than

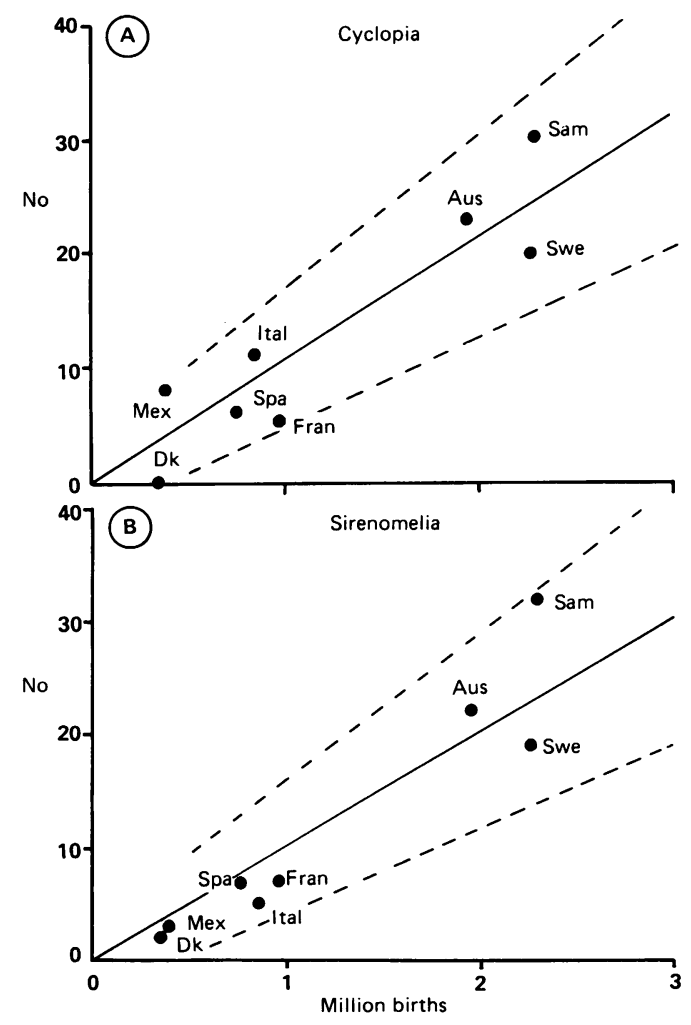

Figure 1 Diagrams showing number of births in each programme and number of malformed infants recorded. Aus = Australia, Dk=Denmark, Fran =France, $R A A$, Ital = Italy, IPIMC, Mex = Mexico, RYVEMCE, Sam = South America, ECLAMC, Spa = Spain, ECEMC, Swe = Sweden. The unbroken line marks the average rate of the malformation and the broken lines the $95 \%$ confidence interval. 
Table 2 Registered infants with trisomy 13 in the programme (not all cases were karyotyped) (rates per 100000 births).

\begin{tabular}{|c|c|c|c|c|c|c|}
\hline Programme & Years & $\begin{array}{l}\text { No } \\
\text { of births }\end{array}$ & $\begin{array}{c}\text { No of } \\
\text { trisomy } 13\end{array}$ & Rate & $\begin{array}{l}\text { No with } \\
\text { malformations }\end{array}$ & $\begin{array}{l}\text { No with } \\
\text { cyclopia }\end{array}$ \\
\hline $\begin{array}{l}\text { Australia } \\
\text { Denmark } \\
\text { France, RAA } \\
\text { Italy, IPIMC } \\
\text { Mexico } \\
\text { South America } \\
\text { Spain } \\
\text { Sweden } \\
\text { Total }\end{array}$ & $\begin{array}{l}1981-1988 \\
1983-1987 \\
1976-1988 \\
1983-1988 \\
1978-1988 \\
1967-1989 \\
1976-1989 \\
1973-1988\end{array}$ & $\begin{array}{r}1798728 \\
328254 \\
1033600 \\
824478 \\
358590 \\
2278771 \\
728368 \\
1079683 \\
8430472\end{array}$ & $\begin{array}{r}161 \\
15 \\
50 \\
54 \\
13 \\
81 \\
28 \\
88 \\
490\end{array}$ & $\begin{array}{l}9 \cdot 0 \\
4 \cdot 0 \\
4 \cdot 8 \\
6 \cdot 5 \\
3 \cdot 6 \\
3 \cdot 6 \\
4 \cdot 1 \\
8 \cdot 2 \\
5 \cdot 8\end{array}$ & $\begin{array}{r}144 \\
13 \\
40 \\
54 \\
13 \\
81 \\
28 \\
63 \\
436\end{array}$ & $\begin{array}{l}3 \\
0 \\
3 \\
1 \\
0 \\
0 \\
1 \\
0 \\
8\end{array}$ \\
\hline
\end{tabular}

during the period 1975 to 1983 and then the rate increases again. The temporal graph will be sensitive to the periods of participation of the different programmes.

SURVIVAL, NECROPSY, AND CYTOGENETICS As stressed above, the stillbirth rate is high. Among infants with cyclopia, 28 were stillbirths and 75 were born alive but died shortly after birth. The corresponding numbers for sirenomelia were 35 stillbirths and 62 livebirths that died shortly after birth. Necropsy was performed in 68 cases of cyclopia and 57 of sirenomelia. Cytogenetic investigations were performed in only nine cases of cyclopia and six of sirenomelia. It is therefore possible that infants with chromosome anomalies were inadvertently included.

SEX

There is an excess of female births among infants with cyclopia, 38 male and 62 female infants, and in three cases (one with sirenomelia) the sex was unknown. There are 15 males and 17 females among the cases of sirenomelia; however, in the majority of cases (65), the sex was unknown. Assigning sex in sirenomelic infants was based on chromosomal or gonadal sex. Among karyotyped trisomy 13 infants with known sex, 158 were males and 160 females. The sex ratio for trisomy 13 is thus close to 1.0 in our material.

\section{TWINNING}

There were seven twin pairs among the infants with cyclopia. In one pair, the sex of the infant

Figure 2 Rate of cyclopia (unbroken line) and sirenomelia (broken line) each year during the observation period, based on moving three year averages. The ratio between the observed and expected number is plotted, the latter calculated from the calculated from the malformation during the whole period in each programme and the number of births each year in that programme.

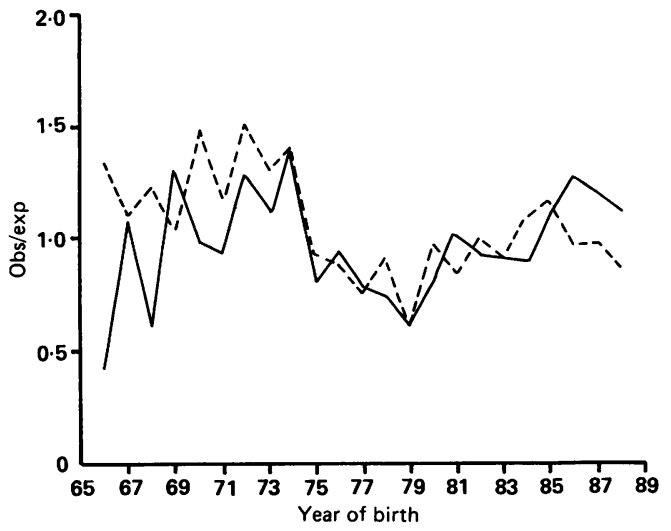

with cyclopia was not known and the co-twin was a microcephalic male. In one pair with a female infant with cyclopia, the sex of the cotwin was not known but it had a congenital hip subluxation. There were two unlike sexed and one like sexed (female) pair with a normal cotwin. In two pairs, no information was available on the co-twin. There was one twin with sirenomelia of unknown sex and with a normal female co-twin and a further two twin pairs without information on the co-twin.

\section{MATERNAL AGE}

Fig 3 shows that there is an apparently increased risk for cyclopia with high maternal age. In sirenomelia, deviations from the expected maternal age distribution are small, but there is an indication of increased risk in
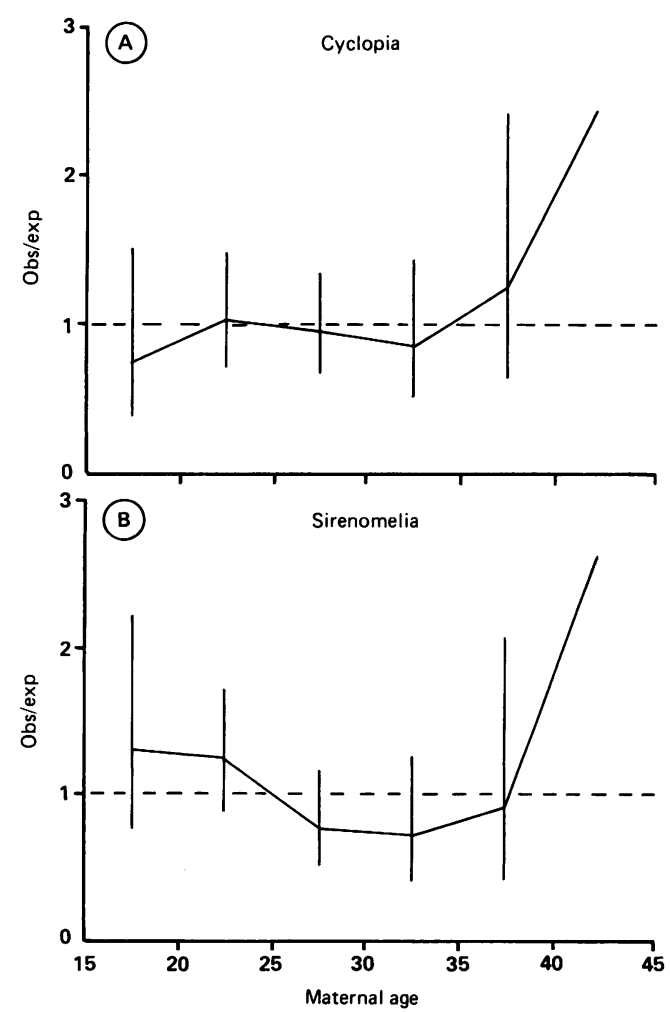

Figure 3 Observed over expected ratio for each maternal age class for $(A)$ cyclopia and $(B)$ sirenomelia. The expected numbers are calculated for each maternal age class from the age distribution of the background population after stratification for programme and year of birth $(95 \%$ confidence intervals are marked with vertical bars). 
young and old women. There were 14 women aged above 35 with cyclopean infants against 8.8 expected $\left(\chi^{2}=3.4,0.10>p>0.05\right)$. The corresponding figures for mothers of sirenomelic infants was 10 against $8.4\left(\chi^{2}=0.75\right.$, NS). Mean maternal age is 30.5 years for cyclopean and 30.4 years for sirenomelic infants.

\section{ASSOCIATED MALFORMATIONS}

Both conditions studied had associated malformations which are direct consequences of the primary developmental defect. Cyclopia is obligatorily associated with holoprosencephaly (and therefore often with microcephaly) because it originates in deficient lateralisation of the early rudiment of the brain. Other median defects in the development of the face may also arise, like median facial clefts or otocephaly. Sirenomelia is obligatorily associated with other severe caudal defects in the spine, absent or malformed kidneys, anal atresia, and absence of external genital organs. Pulmonary hypoplasia and Potter facial anomalies usually occur, related to the kidney malformations.

Postaxial polydactyly is a feature of the most common chromosomal anomaly found with cyclopia, trisomy $13 .{ }^{4}$ Among the 103 cases of cyclopia in the present material, 15 had postaxial polydactyly and in eight of them this was the only malformation outside the cyclopean complex. Among the 14 cases with polydactyly and with known maternal age, seven were over 35 years $(50 \%)$; among the 86 cases without polydactyly and with known maternal age, eight $(9 \%)$ were aged over 35 . This supports the idea that most cases with cyclopia and polydactyly have an undetected trisomy. In one infant with a normal karyotype Meckel syndrome was suspected, and other syndromes like pseudotrisomy $13,{ }^{16} 18 \mathrm{p}-$, 7q-, or interstitial $2 p$ deletion may be included.

Excluding polydactyly, there were 50 cyclopean infants with associated malformations. The malformations involved are shown in table 3. In 10 of them, neural tube defects occurred (six anencephaly, three spina bifida, one encephalocele). Among the 98 sirenomelic infants, 55 were 'isolated', in that there were no associated malformations. Table 3 shows the malformations recorded among the other 43 cases. Among the seven neural tube defects, six were low spina bifida and one was a cervical spina bifida.

It should be noted that one infant had both cyclopia and sirenomelia and has been tabulated under both headings. This infant had sirenomelia with an imperforate anus, cyclopia with microcephaly, and radial agenesis on the right side (fig 4). Table 3 shows that some of the malformations which are directly associated with one condition also occur with the other, for example, otocephaly and sirenomelia, and anal atresia or kidney malformations and cyclopia. Some relatively rare malformations seem to occur at a high rate in both groups of infants, for example, oesophageal atresia and radial defects.
Table 3 Associated malformations found in infants with cyclopia or sirenomelia.

\begin{tabular}{|c|c|c|}
\hline \multirow[b]{2}{*}{ Type of malformations } & \multicolumn{2}{|c|}{ No of cases with } \\
\hline & Cyclopia & Sirenomelia \\
\hline \multicolumn{3}{|l|}{ Central nervous system } \\
\hline Neural tube defects & 10 & 7 \\
\hline Iniencephaly & 1 & 0 \\
\hline Hydrocephalus & - & 2 \\
\hline $\begin{array}{l}\text { Cyclopia } \\
\text { Head and neck }\end{array}$ & - & 1 \\
\hline $\begin{array}{l}\text { Head and neck } \\
\text { Cleft lip/palate }\end{array}$ & 4 & 3 \\
\hline Otocephaly & - & 1 \\
\hline Choanal atresia & 1 & 1 \\
\hline \multicolumn{3}{|l|}{ Gastrointestinal system } \\
\hline Oesophageal atresia & 2 & 8 \\
\hline Tracheal agenesis/atresia & 1 & 1 \\
\hline Anal atresia & 5 & - \\
\hline Malrotation of gut & 2 & 4 \\
\hline Gall bladder agenesis & 1 & 2 \\
\hline Omphalomesenteric duct & 0 & 1 \\
\hline \multicolumn{3}{|l|}{ Heart defects } \\
\hline Septal defects (VSD, ASD) & 7 & 3 \\
\hline Hypoplastic left heart & 2 & 0 \\
\hline Truncus communis & 1 & 3 \\
\hline Single ventricle & 0 & 1 \\
\hline Single atrium & 1 & 0 \\
\hline Tricuspid atresia/single atrium & 0 & 1 \\
\hline Unspecified & 1 & 0 \\
\hline \multicolumn{3}{|l|}{ Body wall defects } \\
\hline Omphalocele & 2 & 0 \\
\hline Celosomia & 0 & 1 \\
\hline Diaphragmatic hernia & 2 & 3 \\
\hline Prune belly & 0 & 1 \\
\hline \multicolumn{3}{|l|}{ Urogenital system } \\
\hline Kidney malformations & 6 & - \\
\hline Double uterus-vagina & 3 & 2 \\
\hline \multirow{2}{*}{\multicolumn{3}{|c|}{ Limb defects }} \\
\hline & & \\
\hline Polydactyly & 7 & 1 \\
\hline Syndactyly & 1 & 0 \\
\hline Talipes & 3 & - \\
\hline Radial defects & 3 & 6 \\
\hline Probable radial defect & 0 & 1 \\
\hline Transverse arm reduction & 1 & 2 \\
\hline Unspecified arm malformation & 1 & 1 \\
\hline Genu recurvatum & 1 & - \\
\hline Absent 5th toe bilaterally & 1 & - \\
\hline Sirenomelia & 1 & - \\
\hline \multicolumn{3}{|l|}{ Other defects } \\
\hline Simian creases & 1 & 1 \\
\hline Thoracic vertebral anomalies & 0 & 2 \\
\hline Fusion of ribs & 0 & 1 \\
\hline Absent lung lobe & 0 & 1 \\
\hline Brachydactyly & 1 & 0 \\
\hline
\end{tabular}

$-=$ obligatory or impossible malformations.

\section{MALFORMATION IN SIBS}

We identified 65 sibs born before a proband with cyclopia, one of whom had hydrocephalus. Of 11 sibs born after a proband with cyclopia, none was malformed. We identified 41 sibs born before a proband with sirenomelia, one of whom had a persistent cloaca. Of 10 sibs born after the sirenomelia probands, none had a major malformation.

\section{Discussion}

Both conditions studied in this paper are extremely rare. We found an approximate prevalence at birth of 1 in 100000 for each malformation. In order to study the epidemiology of such rare conditions, data were pooled from a number of malformation monitoring programmes representing more than 10 million births.

Infants with a known chromosome anomaly were excluded, but most were not studied cytogenetically. It has been estimated that about $50 \%$ of all infants with holoprosencephaly have a chromosome anomaly, ${ }^{17}{ }^{18}$ but it has been suggested that this percentage is in fact lower. ${ }^{4}$ The most common chromosome anomaly associated with holoprosencephaly is 


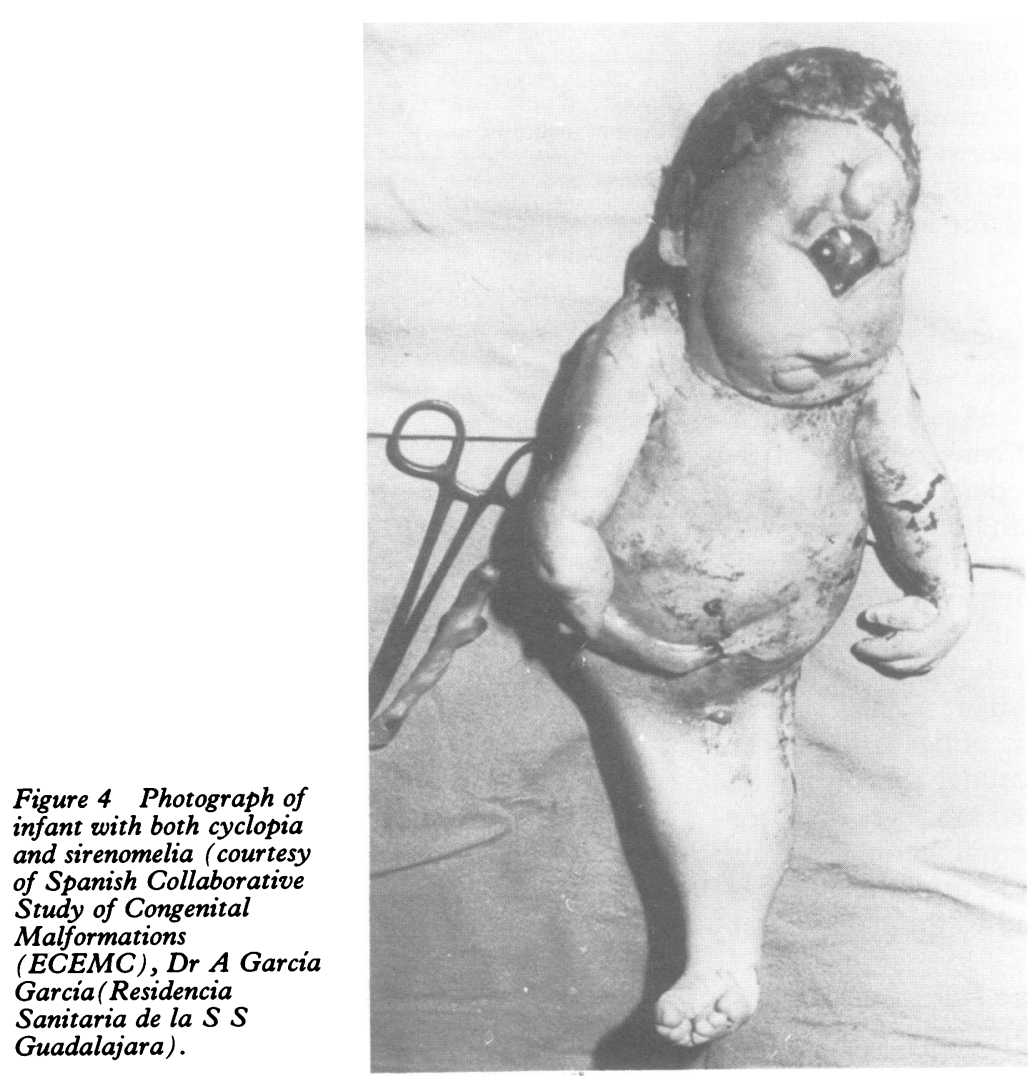

trisomy 13 with an overall prevalence at birth in our material of 1 in 17200 , but although holoprosencephaly is common in trisomy 13, fewer than $3 \%$ of these infants had cyclopia. If chromosomally abnormal cyclopean infants are also included, the prevalence at birth may increase to $1 \cdot 2$ per 100000 .

We found indirect evidence that undetected trisomy 13 cases were included in our material: in cyclopean infants with postaxial polydactyly, a feature of trisomy 13, maternal age was more often above 35 years than in cyclopean infants without polydactyly. Inclusion of unidentified trisomy 13 cases can hardly explain the female excess among cyclopean infants, as the sex ratio of trisomy 13 in our study was close to $1 \cdot 0$. The problem with inclusion or exclusion of chromosome anomalies is of less significance in relation to sirenomelia as these infants are usually chromosomally normal.

Another source of variation in the recorded rate of cyclopean or sirenomelic infants is the inclusion/exclusion of stillbirths in the study and the definition of stillbirths when included. About one-third of all these infants are stillborn and when stillbirths are not included in the material, the prevalence at birth will be underestimated. We estimated that the prevalence at birth of cyclopia is about 1.2 in 100000 and of sirenomelia 1.05 per 100000 . We found no convincing variation in the recorded rates between the programmes, which probably indicates that a variable inclusion of chromosomally abnormal cases does not affect the estimates much.

We found some, but not convincing, evidence of a change in the registered rate with year of birth; however it should be noted that with such rare conditions, moderate changes with time are difficult to quantify.

Unusually, many of the cyclopean infants were twins; given 103 such infants, the expected number of twins would be one or two but we found seven pairs. Among 98 sirenomelic infants three pairs of twins were found. Cyclopia also occurred in dizygotic (unlike sexed) twin pairs and the co-twin was normal except for one pair where it had microcephaly. In a review of published reports, four such pairs were found; in three the co-twin was malformed and only one was normal, but this may be a result of reporting bias. ${ }^{4}$

As the disturbance leading to cyclopia occurs in early embryonic life, some other effects are inevitable, like a severe holoprosencephalic brain and disturbances of the midface. These are therefore direct consequences of the cyclopean state. Similarly, sirenomelia is (nearly always) associated with malformations of the spine or pelvis, absence of or malformed kidneys (with pulmonary hypoplasia and Potter face as a sequence), absence of external genital organs, and anal atresia.

The presence of neural tube defects with both conditions is expected. The association between anencephaly and cyclopia is well known and has been regarded as an expression of the same basic disturbance in the induction of the neural plate. ${ }^{19}$ As the most caudal part of the spine develops from the caudal eminence, the association between low spina bifida and sirenomelia is understandable.

Included in our material is one infant with both cyclopia and sirenomelia. In another sirenomelic case, otocephaly was present, a feature often seen with cyclopia. We also found that malformations which are an obligatory or common consequence of one of the malformation types were often also present with the other type. Furthermore, we found an association between both types of malformation and two relatively rare defects: oesophageal atresia and radial reduction defects. The association between vertebral, anal, oesophagotracheal, and renal/radial defects has been given the acronym VATER ${ }^{20}$ or (including heart and limb defects) VACTERL. ${ }^{21}$ There is some evidence ${ }^{22}$ that cardiac defects do not occur in this complex more often than they occur in any multimalformed infant. It has also been suggested $^{23}$ that the VATER-like infants and those with the syndrome of caudal regression (where sirenomelia is the extreme form) actually form a continuum. It is therefore of special interest that both radial defects and tracheo-oesophageal defects are common not only with sirenomelia but also with cyclopia. It should also be noted that the presence of oesophageal atresia and radial defects may indicate that undetected cases of trisomy 18 are included in the group studied.

This circumstantial epidemiological evidence supports the notion of O'Rahilly and Müller ${ }^{1}$ that cyclopia and sirenomelia actually have a similar mode of formation, and one could speculate that aetiological or pathogenetic factors could be similar for the two conditions. In both conditions there are reasons to 
believe that the basic disturbance is in induction processes where central mesoderm is involved and it is possible that other induction processes can also be disturbed in other parts of the body (for example, during limb bud formation). There is actually one teratogenic condition, maternal diabetes, which has been shown to be associated both with the holoprosencephaly-cyclopia complex ${ }^{24}$ and the caudal regression complex..$^{25}$ Among the cyclopic infants studied in this paper, maternal diabetes was noted in four instances.

1 O'Rahilly $R$, Müller F. Interpretation of some median anomalies as illustrated by cyclopia and symmelia. Teratology 1989;40:409-21.

2 Adelmann HB. A study of cyclopia in Amblystoma punctatum with special reference to the mesoderm. $\mathcal{E}$ Exp Zool 1937;67:219-81.

3 Holmdahl D. Die erste Entwicklung des Körpers bei den Vögeln und Säugetieren, inkl dem Menschen, besonders mit Rücksicht auf die Bildung des Rückenmarks, des Zöloms unter der entodermalen Kloake, nebst einen Exkurs über die Enstehung der Spina bifida in der Lumbosakralregionen. Morphol $f b$ 1925;54:333-84,55:112208.

4 Cohen MM Jr. Perspectives on holoprosencephaly. Part I. Epidemiology, genetics and syndromology. Teratology 1989;40:211-35.

5 Duhamel B. From the mermaid to anal imperforation: the syndrome of caudal regression. Arch Dis Child $1961 ; 36: 152-5$.

6 Källén B, Winberg J. Caudal mesoderm pattern of anomalies: from renal agenesis to sirenomelia. Teratology 1974;9:99-112.

7 Congenital Malformations Worldwise. A report from the International Clearinghouse for Birth Defects Monitoring Systems. Amsterdam: Elsevier, 1991.

8 Lancaster PAL. Health registers for congenital malformations and in vitro fertilization. Clin Reprod Fertil 1986;4:27-37.

9 National Board of Health. Registry on Congenital Malformations 1984-1985. In: Vitalstatistik. I:18. Copenhagen: Sundhedsstyrelsen, 1986 (in Danish with English subtitles and summary).

10 Robert E, Francannet C, Robert JM. Le registre de malformations de la région Rhone-Alps/Auvergne. Intérèt et limites de la tératovigilance. Onze années d'expérience (1976-1986) F Gynecol Obstet Biol Reprod 1988;17:601-7.

11 Mastroiacovo P. The Italian birth defects monitoring system: baseline rates based on 283453 births and comparison with other registries. In: Prevention of physical and mental congenital defects, Part B. Epidemiology, early detection and therapy, and environmental factors. New York: Alan R Liss, 1985:17-21.

12 Mutchinick O, Lisker R, Babinsky V. Programa Mexicano de 'Registro y vigilancia epidemiólogica de malformaciones congéntias externas'. Salud Pública Mex 1988;30:88-100.

13 Castilla EE, Orioli IM. El estudio colaborativa Latinoamericano de malformaciones congenitas: ECLAMC/MONITOR. Interciencia 1983;8:271-8.

14 Martinez-Frias ML, Salvador J, Prieto L, Zaplana J. Epidemiological study of gastroschisis and omphalocele in Spain. Teratology 1984;29:377-82.

15 Källén B, Winberg J. A Swedish register of congenital malformations. Experience with continuous registration during 2 years with special reference to multiple malformations. Pediatrics 1968;41:765-76.

16 Atkin JP. A new syndrome with cyclopia and trisomy 13 features. Am F Hum Genet 1988; suppl 43:A143.

17 Laurence KM, Ishmael J. Arrhinencephaly and 13-15(D) trisomy. Oxford Chromosome Conference. Chromosomes Today. 1969: proc 2,86-9, (quoted from Cohen 1989).

18 Ming PM, Goodner DM, Park TS. Cytogenetic variants in holoprosencephaly. Am $\mathcal{F}$ Dis Child 1976;130:864-7.

19 Källén B. Errors in the differentiation of the central nervous system. In: Handbook of clinical neurology. Vol 6. Malformations. Amsterdam: Elsevier, 1987:19-47.

20 Quan L, Smith DW. The VATER association: vertebral defect, anal atresia, T-E fistula with esophageal atresia, radial and renal dysplasia: a spectrum of associated deradial and renal dysplasia: a spec

21 Nora AH, Nora JJ. A syndrome of multiple congenital anomalies associated with teratogenic exposure: the VACTERL syndrome. Arch Environ Health 1975;30:17-21.

22 Källén B. Population surveillance of multimalformed in fants. Experience with the Swedish registry of congenital malformations. Second part. F Genet Hum 1987;35:32138.

23 Källèn B. Caudal aplasia. In: Handbook of clinical neurology. Vol 6. Malformations. Amsterdam: Elsevier, 1987;509-18. 24 Barr M, Hanson JW, Currey K, et al. Holoprosencephaly in infants of diabetic mothers. $\mathcal{F}$ Pediatr 1983;102:565-8.

25 Passarge E, Lenz W. Syndrome of caudal regression in infants of diabetic mothers. Observations of further cases. Pediatrics 1966;37:672-5. 